\title{
NMDA Receptors Mediate Neuron-to-Glia Signaling in Mouse Cortical Astrocytes
}

\author{
Ulyana Lalo, ${ }^{1}$ Yuri Pankratov, ${ }^{1}$ Frank Kirchhoff, ${ }^{2,3}$ R. Alan North, ${ }^{1}$ and Alexei Verkhratsky ${ }^{1}$ \\ ${ }^{1}$ Faculty of Life Sciences, The University of Manchester, Manchester M13 9PT, United Kingdom, ${ }^{2}$ Max Planck Institute of Experimental Medicine and \\ ${ }^{3}$ Deutsche Forschungsgemeinschaft Research Center for Molecular Physiology of the Brain, D-37075 Goettingen, Germany
}

Chemical transmission between neurons and glial cells is an important element of integration in the CNS. Here, we describe currents activated by NMDA in cortical astrocytes, identified in transgenic mice that express enhanced green fluorescent protein under control of the human glial fibrillary acidic protein promoter. Astrocytes were studied by whole-cell voltage clamp either in slices or after gentle nonenzymatic mechanical dissociation. Acutely isolated astrocytes showed a three-component response to glutamate. The initial rapid component was blocked by 1,2,3,4-tetrahydro-6-nitro-2,3-dioxo-benzo[f]quinoxaline-7-sulfonamide (NBQX), which is an antagonist of AMPA receptors $\left(\mathrm{IC}_{50}, 2 \mu \mathrm{M}\right)$, and the NMDA receptor antagonist D-AP-5 blocked the later sustained component $\left(\mathrm{IC}_{50}, 0.6 \mu \mathrm{M}\right)$. The third component of glutamate application response was sensitive to D,L-threo- $\beta$-benzyloxyaspartate, a glutamate transporter blocker. Fast application of NMDA evoked concentration-dependent inward currents $\left(\mathrm{EC}_{50}, 0.3 \mu \mathrm{M}\right)$; these showed use-dependent block by $(+)-5$ methyl-10,11-dihydro-5H-dibenzo [a,d] cyclohepten-5,10-imine maleate (MK-801). These NMDA-evoked currents were linearly dependent on membrane potential and were not affected by extracellular magnesium at concentrations up to $10 \mathrm{~mm}$. Electrical stimulation of axons in layer IV-VI induced a complex inward current in astrocytes situated in the cortical layer II, part of which was sensitive to MK-801 at holding potential $-80 \mathrm{mV}$ and was not affected by the AMPA glutamate receptor antagonist NBQX. The fast miniature spontaneous currents were observed in cortical astrocytes in slices as well. These currents exhibited both AMPA and NMDA receptor-mediated components. We conclude that cortical astrocytes express functional NMDA receptors that are devoid of $\mathrm{Mg}^{2+}$ block, and these receptors are involved in neuronal-glial signal transmission.

Key words: NMDA receptors; $\mathrm{Mg}^{2+}$ insensitivity; cortex; GFAP-GFP mice; astrocytes; neuronal-glial interactions

\section{Introduction}

Brain function ultimately depends on the interaction between two cellular circuits, the electrically excitable neuronal network and electrically nonexcitable astroglial syncytium (Volterra and Meldolesi, 2005). This interaction is accomplished either through transmitters, which signal reciprocally between neurons and astrocytes (Verkhratsky and Kettenmann, 1996; Verkhratsky et al., 1998; Araque et al., 2001; Haydon, 2001) or via neuronal-astroglial electrical synapses formed by gap junctions (Nedergaard, 1994; Nadarajah et al., 1996; Alvarez-Maubecin et al., 2000; Pakhotin and Verkhratsky, 2005).

Glutamate-mediated signaling from neurons to glial cells is executed through three main pathways. These are (1) activation of ionotropic glutamate receptors with consequent generation of ion fluxes (Clark and Barbour, 1997; Seifert et al., 1997; Verkhratsky and Steinhauser, 2000; Matsui et al., 2005), (2) activation of metabotropic glutamate receptors leading to intracellular $\mathrm{Ca}^{2+}$ release (Grosche et al., 1999; Kirischuk et al., 1999), and (3) activation of glutamate transporters, which produce synergistic

Received June 1, 2005; revised Dec. 30, 2005; accepted Jan. 3, 2006.

This work was supported by The Wellcome Trust and the National Institutes of Health.

Correspondence should be addressed to Prof. Alexei Verkhratsky, Faculty of Life Sciences, The University of Manchester, 1.124Stopford Building, Oxford Road, Manchester M13 9PT, UK. E-mail: alex.verkhratsky@manchester.ac.uk. DOI:10.1523/JNEUROSCI.4689-05.2006

Copyright $\odot 2006$ Society for Neuroscience $\quad 0270-6474 / 06 / 262673-11 \$ 15.00 / 0$ influx of glutamate and $\mathrm{Na}^{+}$into astrocytes and accompanying ionic current (Huang et al., 2004; Marcaggi and Attwell, 2004; Wallraff et al., 2004). Ionotropic glutamate receptors were initially discovered in cultured astrocytes (Bowman and Kimelberg, 1984; Kettenmann et al., 1984), and subsequently functional expression of these receptors was confirmed in brain slices acutely isolated from various brain regions including cerebellum, hippocampus, and brainstem (Muller et al., 1992; Steinhauser and Gallo, 1996; Clark and Barbour, 1997; Matthias et al., 2003). Using pharmacological and molecular approaches, astroglial expression of two main subtypes of glutamate receptors, AMPA receptors and kainate receptors, was firmly established (Burnashev et al., 1992; Jabs et al., 1994; Seifert et al., 1997; Condorelli et al., 1999; Verkhratsky and Steinhauser, 2000). Analysis of the functional expression of the third main type of ionotropic glutamate receptor, the NMDA receptor, in astrocytes turned out to be more complicated and revealed significant differences to neuronal NMDA receptors known from in situ or ectopic expression studies (Schipke et al., 2001).

Subunits of NMDA receptors (NR1 and NR2A/B) and expression of NMDA receptor mRNA were detected in astrocytes by immunohistochemistry, in situ hybridization, and PCR (Conti et al., 1996, 1997; Van Bockstaele and Colago, 1996; Schipke et al., 2001). Several functional studies demonstrated NMDAmediated currents and NMDA-induced $\left[\mathrm{Ca}^{2+}\right]_{\mathrm{i}}$ responses in 
cultured astrocytes (Kondoh et al., 2001) and in astrocytes in situ (Muller et al., 1993; Shao and McCarthy, 1997; Ziak et al., 1998; Schipke et al., 2001). However, in some cases, these responses were blocked by tetrodotoxin (Shao and McCarthy, 1997), suggesting indirect effects of the agonist. Recordings from identified astrocytes in slices revealed rather slow currents (Schipke et al., 2001), which did not resemble classic NMDA receptor-mediated responses. Here, we present a study of NMDA-induced currents in identified cortical astrocytes and show that these can also be activated by glutamate released after stimulation of neuronal synaptic terminals as well as during spontaneous release of neurotransmitter.

\section{Materials and Methods}

Slice preparation. Experiments were performed on transgenic mice expressing enhanced green fluorescent protein (EGFP) under the control of the human glial fibrillary acidic protein (GFAP) promoter [line $T g N(G F A P$ EGFP)GFEC-FKi]. This line has been generated similarly to the line [now designated $\operatorname{TgN}(G F A P-E G F P) G F E A-F K i]$ described the first time by Nolte et al. (2001) and further studied by Schipke et al. (2001), Malatesta et al. (2003), Matthias et al. (2003), Grass et al. (2004), and Hirrlinger et al. (2004). The most significant difference of the GFEC line is the higher percentage of so-called classic or protoplasmic astrocytes expressing high levels of EGFP in the cortex, hippocampus, and brainstem (F. Kirchhoff, unpublished observation). The animals (17-22 d of age) were anesthetized by halothane and then decapitated, in accordance with United Kingdom legislation. Slices were prepared using the technique described previously (Pankratov et al., $2002,2003)$. Brains were dissected rapidly and placed in the physiological saline containing the following (in $\mathrm{mm}$ ): $135 \mathrm{NaCl}, 3 \mathrm{KCl}, 1 \mathrm{MgCl}_{2}, 2.4$ $\mathrm{CaCl}_{2}, 26 \mathrm{NaHCO}_{3}, 1 \mathrm{NaH}_{2} \mathrm{PO}_{4}$, and 15 glucose, $\mathrm{pH} 7.4$ when gassed with $95 \% \mathrm{O}_{2} / 5 \% \mathrm{CO}_{2}$. Brain slices ( $300 \mu \mathrm{m}$ thick) were cut at $4{ }^{\circ} \mathrm{C}$ and kept at room temperature for $1-4 \mathrm{~h}$ before the recordings were made.

Acute isolation of astrocytes. Astrocytes were acutely isolated using the modified "vibrating ball" technique (Vorobjev, 1991; Pankratov et al., 2002, 2003; Akaike and Moorhouse, 2003). The glass ball (diameter, 200 $\mu \mathrm{m}$ ) was moved slowly some $10-50 \mu \mathrm{m}$ above the slice surface, while vibrating at $100 \mathrm{~Hz}$ (lateral displacements, $20-30 \mu \mathrm{m}$ ). The composition of external solution for isolated cell experiments was the following (in mM): $135 \mathrm{NaCl}, 2.7 \mathrm{KCl}, 2.5 \mathrm{CaCl}_{2}, 1 \mathrm{MgCl}_{2}, 10$ HEPES, $1 \mathrm{NaH}_{2} \mathrm{PO}_{4}$, and 15 glucose, $\mathrm{pH}$ adjusted with $\mathrm{NaOH}$ to 7.3 .

Identification of astrocytes. Astrocytes in slices and in single-cell preparation were identified by EGFP fluorescence. For this purpose, the slices or isolated cells were illuminated at $490 \mathrm{~nm}$ and observed at $510 \pm 10 \mathrm{~nm}$. All cells identified visually demonstrated an electrophysiological signature characteristic of astrocytes. A series of depolarizing and hyperpolarizing voltage steps from a holding potential of $-80 \mathrm{mV}$ evoked passive currents, with nearly linear $I-V$ relationship (see Figs. 1, 4, 7).

Electrophysiological recordings. Whole-cell voltage-clamp recordings from isolated cells or from identified astrocytes situated in the layer II of cortical slices were made with patch pipettes (3.5-4 M $\Omega$ ) filled with intracellular solution containing the following (in $\mathrm{mm}$ ): $110 \mathrm{KCl}, 10$ $\mathrm{NaCl}, 10$ HEPES, $5 \mathrm{MgATP}$, and 0.2 EGTA, pH 7.35. The membrane potential was clamped at $-80 \mathrm{mV}$ unless stated otherwise. Currents were

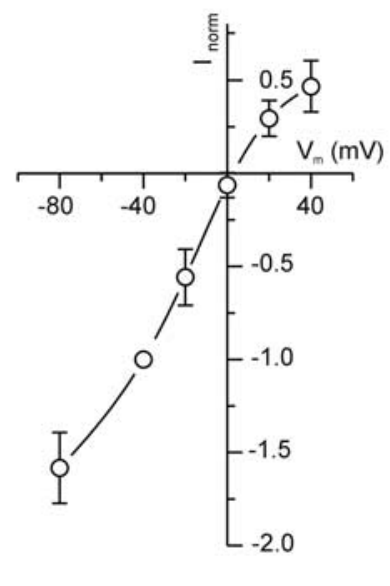

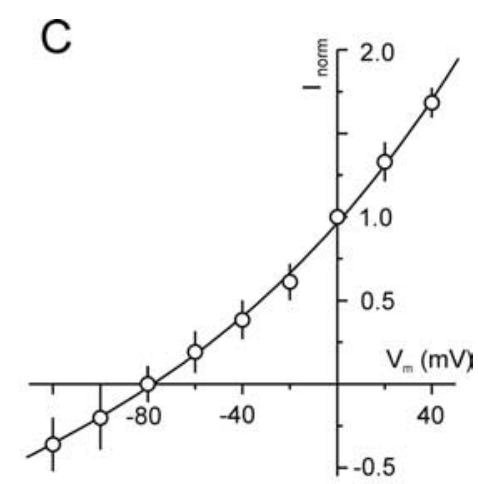

$40 \mathrm{mV}$

$20 \mathrm{mV}$

$0 \mathrm{mV}$

$-20 \mathrm{mV}$

$-40 \mathrm{mV}$

$-80 \mathrm{mV}$

$100 \mathrm{pA}$

$500 \mathrm{~ms}$

Figure 1. Identification of astrocytes after mechanical isolation and the effect of glutamate on an individual astroglial cell. $\boldsymbol{A}$, potentials as indicated. The right panel shows an $I-V$ curve constructed from 11 independent experiments. The amplitudes of currents were normalized to the value measured at $-40 \mathrm{mV}\left(I_{\text {norm }}\right)$.

monitored using EPC-9 (HEKA, Lambrecht, Germany), filtered at 3 $\mathrm{kHz}$, and stored on the disk for off-line analysis. Liquid junction potentials were measured with the EPC-9 patch-clamp amplifier and Pulse software; all voltages reported are corrected. Recordings commenced 10 min after whole-cell access was gained to ensure equilibration between the pipette solution and the cytosol. The series resistances were 4-12 $\mathrm{M} \Omega$, and input resistances were 50-100 $\mathrm{M} \Omega$ for astrocytes and 300-900 $\mathrm{M} \Omega$ for neurons, respectively, and varied by $<20 \%$ in the cells accepted for analysis. A modified "square-pulse" concentration jump method (Lalo et al., 2001; Pankratov et al., 2003) was used for rapid (solution exchange time, $\sim 20 \mathrm{~ms}$ ) applications of solutions containing various agents to single cells. Experiments were controlled by Pulse/PulseFit software (HEKA), and data were analyzed by self-designed software installed on a Windows NT workstation (Microsoft, Redmond, WA).

For activating synaptic inputs, axons originating from layer IV-VI neurons were stimulated at $0.3 \mathrm{~Hz}$ with a bipolar coaxial electrode (Harvard Apparatus, Edenbridge, UK). The electrode was placed in the layer IV approximately opposite the site of recordings. Stimuli were single pulses $(300 \mu \mathrm{s})$ of magnitude adjusted to produce a synaptically evoked response that was about two-thirds of the maximal (typically 10-15 V).

Data analysis. All data are presented as mean $\pm \mathrm{SD}$, unless indicated otherwise. Data on concentration dependence of the effects of antagonists were fitted with the following: $I / I_{0}=1 /\left(1+\left([B] / \mathrm{IC}_{50}\right)^{n}\right)$, where $I$ is the current measured with drug concentration $[B], I_{0}$ is the current in control conditions, and $n$ is a Hill coefficient. Data on concentration dependence of agonists were fitted with the following: $I / I_{\max }=$ $1 /\left(1+\left(\mathrm{EC}_{50} /[A]\right)^{n}\right)$, where $I$ is the current evoked by agonist concentra- 
tion $[A], I_{\max }$ is the maximal current with the highest $[A]$ tested, and $n$ is a Hill coefficient.

The spontaneous currents were analyzed off-line using the method described by Pankratov and Krishtal (2003). For the initial detection of spontaneous events, inward currents of amplitude higher than 2 SD of baseline noise were selected. Subsequently, each spontaneous event was analyzed within the $140 \mathrm{~ms}$ time window (40 ms before and $100 \mathrm{~ms}$ after peak of current). The amplitude of miniature spontaneous currents was determined using a computer routine based on the fitting of each current trace by the model curve with single exponential rise and decay phases. The minimal square root procedure was used to determine the amplitude of the model curve, whereas the time constants and offset were optimized by the gradient method to minimize the mean square error. As a rule, mean square error of fit amounted to $5-20 \%$ of current amplitude, depending on baseline noise. Whenever error of fit exceeded $25 \%$, currents were discarded from further analysis. The amplitude of the synaptic events accepted for analysis was determined as amplitude of the fitted curve. As demonstrated previously (Pankratov and Krishtal, 2003), such a technique is tolerant to noise and enables to obtain the noise-free amplitude distribution of miniature synaptic currents. The amplitude distributions of spontaneous currents were analyzed with the aid of probability density functions and likelihood maximization techniques, as described by Stricker et al. (1996) and Pankratov and Krishtal (2003).

Drugs. The following compounds were used: glutamate, NMDA, 1,2,3,4-tetrahydro-6-nitro-2,3-dioxo-benzo[f] quinoxaline-7-

sulfonamide (NBQX), 2-amino-5-phosphonovaleric acid (D-AP-5), and DL-threo- $\beta$-benzyloxyaspartate (DL-TBOA) (Tocris Bioscience, Bristol, UK). Other salts and chemicals were from Sigma (Dorset, UK).

\section{Results}

Currents in acutely isolated astrocytes evoked by glutamate

Recordings from visually identified, fluorescent astrocytes (Fig. 1A) were made within 30-40 min after isolation. All the cells had current-voltage relationships close to linear (Fig. $1 B, C$ ), typical for protopolasmic astrocytes (Matthias et al., 2003). Application of glutamate evoked an inward current in 39 of 41 cells tested. The current-voltage relationship for the glutamate-induced current was determined by applying $10 \mu \mathrm{M}$ of glutamate at different holding potentials ( -80 to $40 \mathrm{mV}$ ); this was approximately linear (Fig. 1D) for all 11 cells tested.

The current activated by glutamate typically had an initial rapidly rising phase and then declined within 200-300 ms into a smaller sustained component (Fig. 1D). These two components demonstrated distinct sensitivity to pharmacological inhibitors of ionotropic glutamate receptors. NBQX, an inhibitor of AMPA/kainate receptors (Randle et al., 1992), suppressed the initial, rapid peak of the response $\left(\mathrm{IC}_{50}, 2.2 \pm 0.4 \mu \mathrm{M} ; n=4\right.$ ) (Fig. $2 A)$. The sustained component of the glutamate-induced current was inhibited by D-AP-5, a blocker of NMDA receptors $\left(\mathrm{IC}_{50}\right.$, $0.64 \pm 0.1 \mu \mathrm{M} ; n=5$ ) (Fig. $2 B$ ). When cells were treated with a mixture of NBQX $(30 \mu \mathrm{M})$ and D-AP-5 $(10 \mu \mathrm{M})$, the current induced by fast application of $10 \mu \mathrm{M}$ glutamate was blocked by $87 \pm 6 \%(n=6)$ (Fig. $2 C)$. The residual (i.e., resistant to D-AP-5 and NBQX) current was sensitive to glutamate transporter blocker DL-TBOA $(100 \mu \mathrm{M})$. In the presence of the latter, the amplitude of residual current was reduced the by $52 \pm 11 \%$ ( $n=$ 6); DL-TBOA also modified the kinetics of residual current by eliminating its rapid component.

Therefore, glutamate triggered a complex current response resulted from activation of ionotropic receptors and glutamate transporters. To determine the glutamate concentration dependence for each component, we recorded responses to different concentrations of glutamate in the presence of either NBQX or D-AP-5 and in the presence of both antagonists to assess the glutamate sensitivity of the transporter current (Fig. 3). Using
A

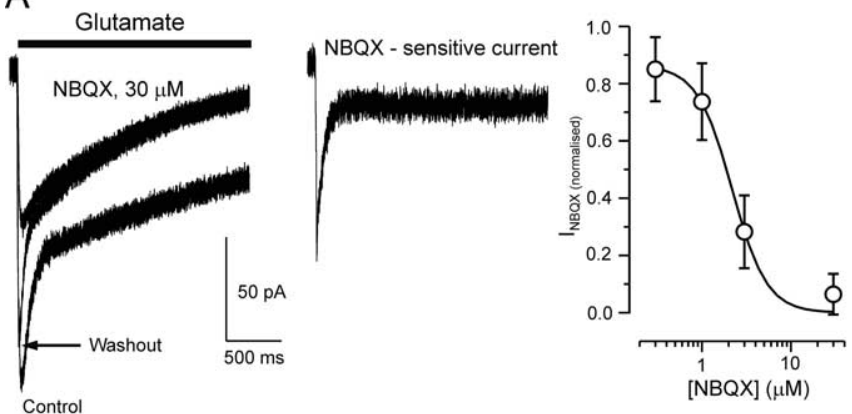

B Glutamate

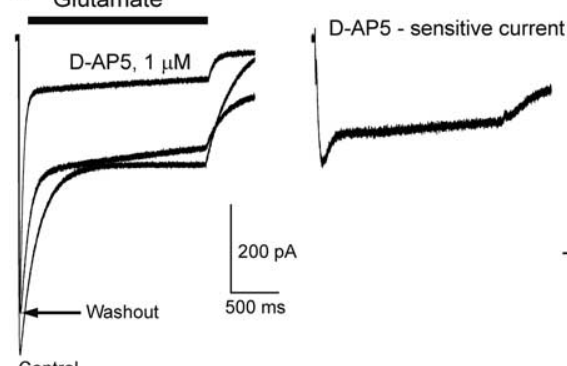

Control
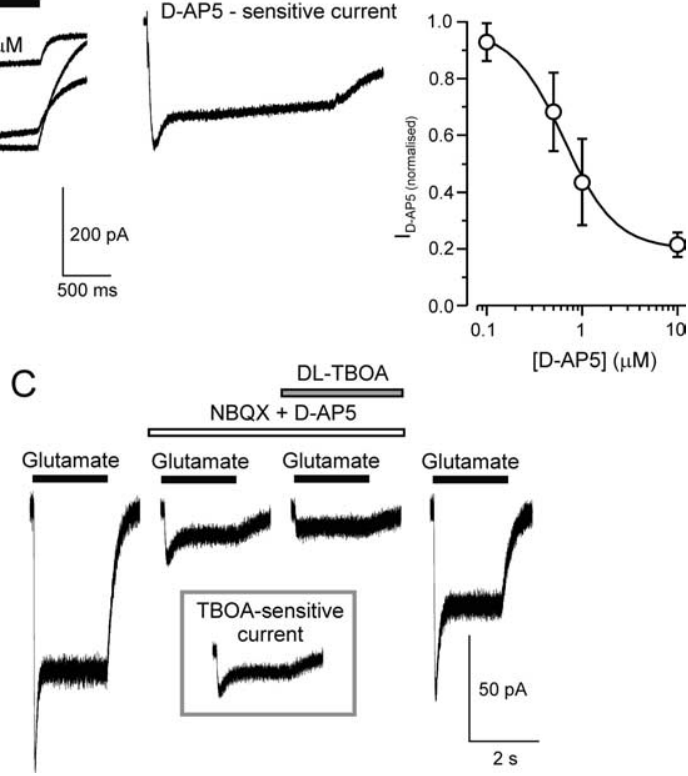

Figure 2. Selective AMPA and NMDA antagonists differentially suppress glutamate-induced current in single astrocytes. $A, N B Q X$ inhibits the fast component of glutamate-induced current. Representative traces illustrate the current before, during, and after application of $30 \mu \mathrm{N} N B Q X$ (left) and the NBQX-sensitive current obtained by subtraction (middle). The right panel shows the concentration dependence of the block of the fast component for four cells $\left(\mathrm{IC}_{50}, 2.2 \pm 0.4\right.$ $\mu \mathrm{m}$; Hill coefficient, 1.9). B, D-AP-5 inhibits the slow component of glutamate-induced current. Representative traces demonstrating the effect of $1 \mu \mathrm{M} \mathrm{D}$-AP-5 (left) and the D-AP-5-sensitive component obtained by subtraction (middle) are shown. The right panel shows the concentration dependence of the block for five cells $\left(\mathrm{IC}_{50}, 0.64 \pm 0.1 \mu \mathrm{m}\right.$; Hill coefficient, 1.6). Error bars represent SD. C, NBQX (30 $\mu \mathrm{M})$ and D-AP-5 (10 $\mu \mathrm{M})$ applied together inhibit both the fast and slow current components. The residual current is sensitive to glutamate transporter blocker DL-TBOA $(100 \mu \mathrm{M})$. The inset shows the trace of DL-TBOA-sensitive component of residual current obtained by digital subtraction.

digital subtraction, we were able to reveal the NMDA- and AMPA-dependent currents in the net form (Fig. $3 A c, B c$ ), and we found that the NMDA receptors were much more sensitive to glutamate $\left(\mathrm{EC}_{50}, 1.9 \pm 0.5 \mu \mathrm{M} ; n=9\right)$ (Fig. $4 \mathrm{Ad}$ ) than AMPA receptors $\left(\mathrm{EC}_{50}, 52 \pm 14 \mu \mathrm{M} ; n=8\right.$ ) (Fig. $4 \mathrm{Be}$ ).

Glutamate transporter currents were also concentration dependent (Fig. $3 B b$ ), but peak and steady-state currents demonstrated different sensitivity to the agonist (Fig. $3 B d$ ). The $\mathrm{EC}_{50}$ for glutamate were $39.8 \pm 13.8 \mu \mathrm{M}$ for peak of response and $3.94 \pm$ $1.6 \mu \mathrm{M}$ for the steady-state component $(n=6)$. The different sensitivity of the peak and steady-state components of glutamate transporter current in cortical astrocytes is similar to concentration dependence of current mediated by glutamate transporter-1 transporter expressed in human embryonic kidney 293 cells (Bergles et al., 2002). At the same time, a noncomplete inhibition 
by DL-TBOA suggests the presence of other transporters (e.g., excitatory amino acid transporter 4); similar incomplete inhibition of glutamate transporter currents by DL-TBOA was also observed by others (Jabaudon et al., 1999).

These results indicate that glutamate activates two populations of glutamate receptors with a distinct sensitivity to AMPA and NMDA receptor blockers and glutamate transporters; in subsequent experiments, we concentrated on investigating the NMDA receptor-mediated component.

\section{Currents in acutely isolated astrocytes} evoked by NMDA

NMDA evoked concentration-dependent inward currents in 47 of 54 tested astrocytes at a holding potential $-80 \mathrm{mV}$ (Fig. $4)$. The threshold concentration was $\sim 30$ $\mathrm{nM}$, and the $\mathrm{EC}_{50}$ was $0.34 \pm 0.06 \mu \mathrm{M}(n=$ 6) (Fig. $4 A$ ). This value is close to the $\mathrm{EC}_{50}$ reported for cloned NMDA receptors (Wyllie et al., 1996; Chen et al., 2001). The NMDA currents were potentiated by glycine, a classical positive modulator of NMDA receptors (Fig. $4 B$ ); the $\mathrm{EC}_{50}$ of glycine effect was $1.1 \pm 0.07 \mu \mathrm{M}(n=7)$.

The time course of the NMDA-induced current was generally similar to that reported for various types of neurons or heterologous expression systems (Mayer et al., 1984, Huettner and Bean, 1988), but the voltage dependence was quite different. Indeed, the finding that robust currents were observed at $-80 \mathrm{mV}$ in a normal extracellular solution (containing 1 $\mathrm{mM} \mathrm{Mg}^{2+}$ ) clearly distinguishes the currents from those observed in neurons (Nowak et al., 1984; Mori and Mishina, 1995; Gotz et al., 1997).

We therefore compared the properties of NMDA currents (evoked in the presence of $1 \mathrm{mM}$ extracellular $\mathrm{Mg}^{2+}$ ) in astrocytes and neurons, mechanically isolated from the same slice. The neurons can be readily distinguished morphologically (attached dendrites, lack of fluorescence) and electrophysiologically (prominent rapidly activating currents elicited by depolarization) (Fig. 4A,D). The current evoked by NMDA $(10 \mu \mathrm{M})$ in astrocytes was almost linearly related to membrane potential ( -80 to $40 \mathrm{mV})$; the reversal potential was $-3.3 \pm 2.8 \mathrm{mV}(n=8)$ (Fig. $4 C$, right). The current evoked by NMDA $(10 \mu \mathrm{M})$ in neurons was maximal at $-40 \mathrm{mV}$, and the current-voltage relationship showed a negative conductance slope between -80 and $-40 \mathrm{mV}(n=4)$ (Fig. $4 D$, right). This is classically indicative of magnesium block at hyperpolarized potentials (Mayer et al., 1984; Nowak et al., 1984; Johnson and Ascher, 1990; Mori and Mishina, 1995). Therefore, we may assume that the linear current-voltage relationship for NMDA response in astrocytes is

A

a a $\quad$ b $\quad$ C
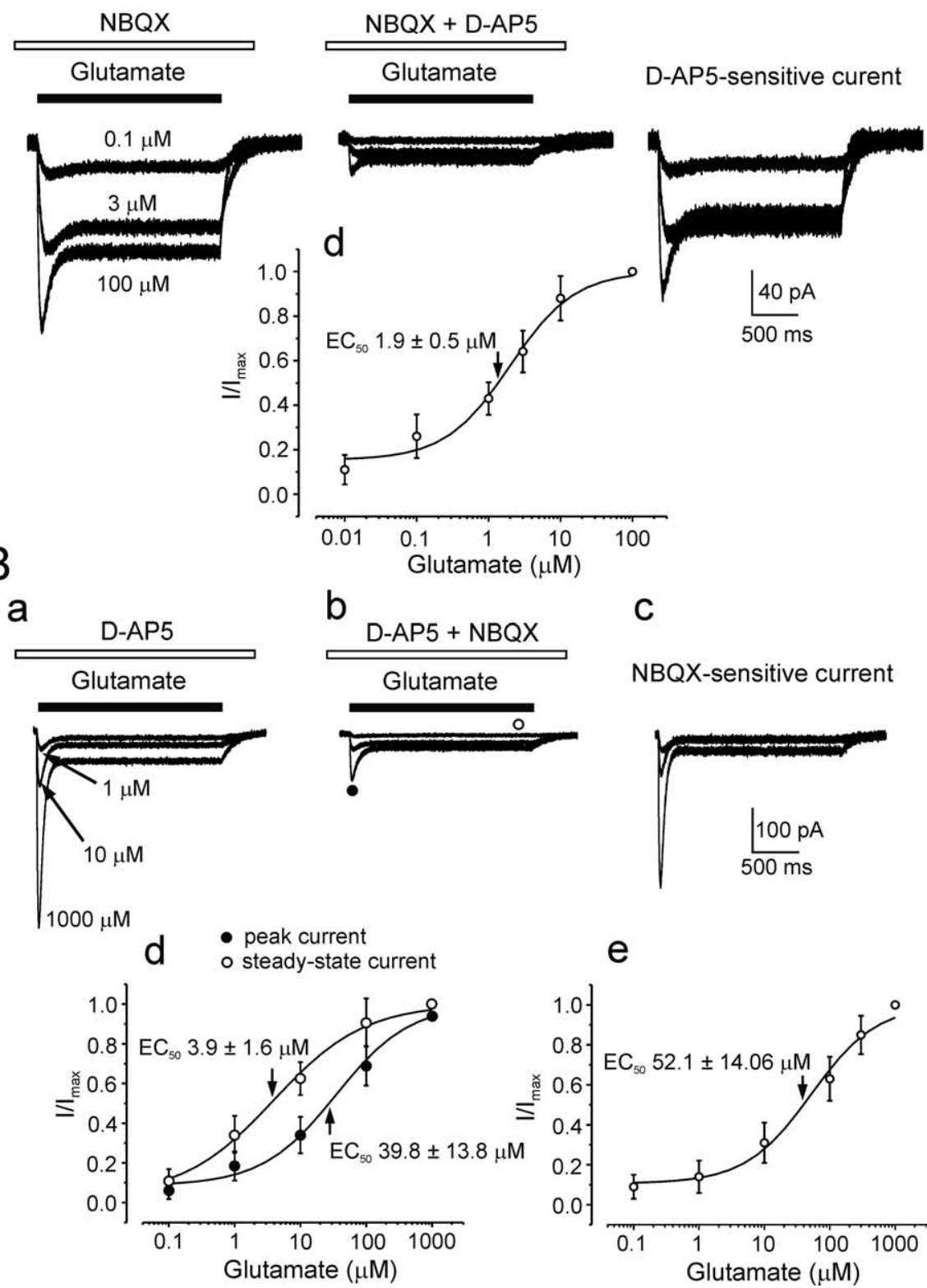

Figure 3. Concentration dependences of glutamate receptor-mediated and glutamate transporter-mediated currents in cortical astrocytes. Aa-Ac, Protocol of pharmacological isolation of NMDA receptor-mediated current. Responses to 2-s-long application of different concentrations of glutamate were recorded in the presence of $30 \mu \mathrm{M} \mathrm{NBQX}(\boldsymbol{A a})$ and in the presence of NBQX and $30 \mu \mathrm{M}$ D-AP-5 $(\boldsymbol{A} \boldsymbol{b})$. Ac, The net NMDA receptor-mediated current component obtained by subtracting the residual current (recorded under NBQX and D-AP-5) from current recorded under NBQX. Ad, Glutamate concentration dependence for D-AP-5sensitive current ( $\mathrm{EC}_{50}, 1.9 \pm 0.5 \mu \mathrm{m}$; Hill coefficient, 1.5) averaged for nine cells. $\mathbf{B a}-\mathbf{B} \boldsymbol{c}$, Isolation of AMPA receptor-mediated current in response to glutamate using protocol similar to that described for $\boldsymbol{A}$. $\boldsymbol{B} \boldsymbol{d}$, Concentration dependence for peak and steady-state components of residual glutamate transporter-mediated current averaged for 17 cells; glutamate $\mathrm{EC}_{50}$ values were $39.8 \pm 13.8$ and $3.9 \pm 1.6 \mu \mathrm{m}$ for peak and steady-state currents, respectively. Be, Concentration dependence for AMPA receptor-mediated component of glutamate-evoked current ( $\mathrm{EC}_{50}, 52 \pm 14 \mu \mathrm{m}$; Hill coefficient, 1.4) obtained from eight cells. All recordings were made at a holding potential of $-80 \mathrm{mV}$. Error bars represent SD.

unlikely an artifact of cell isolation procedure. Moreover, in our recordings from astrocytes, the current-voltage curves were close to linear in solutions containing $0 \mathrm{mM}$ ( $n=3$ cells tested), $5 \mathrm{mM}$ $(n=4)$, and $10 \mathrm{~mm} \mathrm{Mg}^{2+}(n=4)$ (Fig. 5$)$. We observed only a very weak effect of magnesium at $10 \mathrm{~mm}$ concentration.

The NMDA-induced currents recorded from isolated astrocytes were blocked by $(+)$-5-methyl-10,11-dihydro-5H-dibenzo 

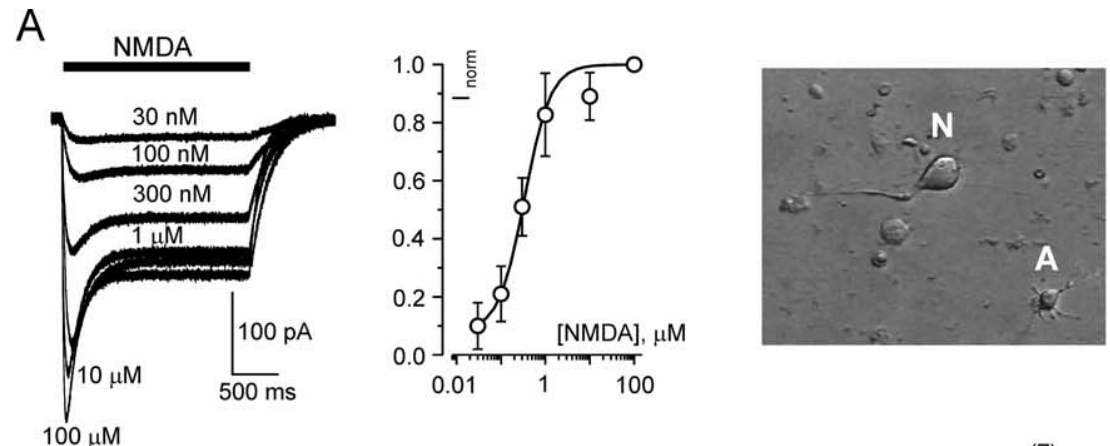

B NMDA
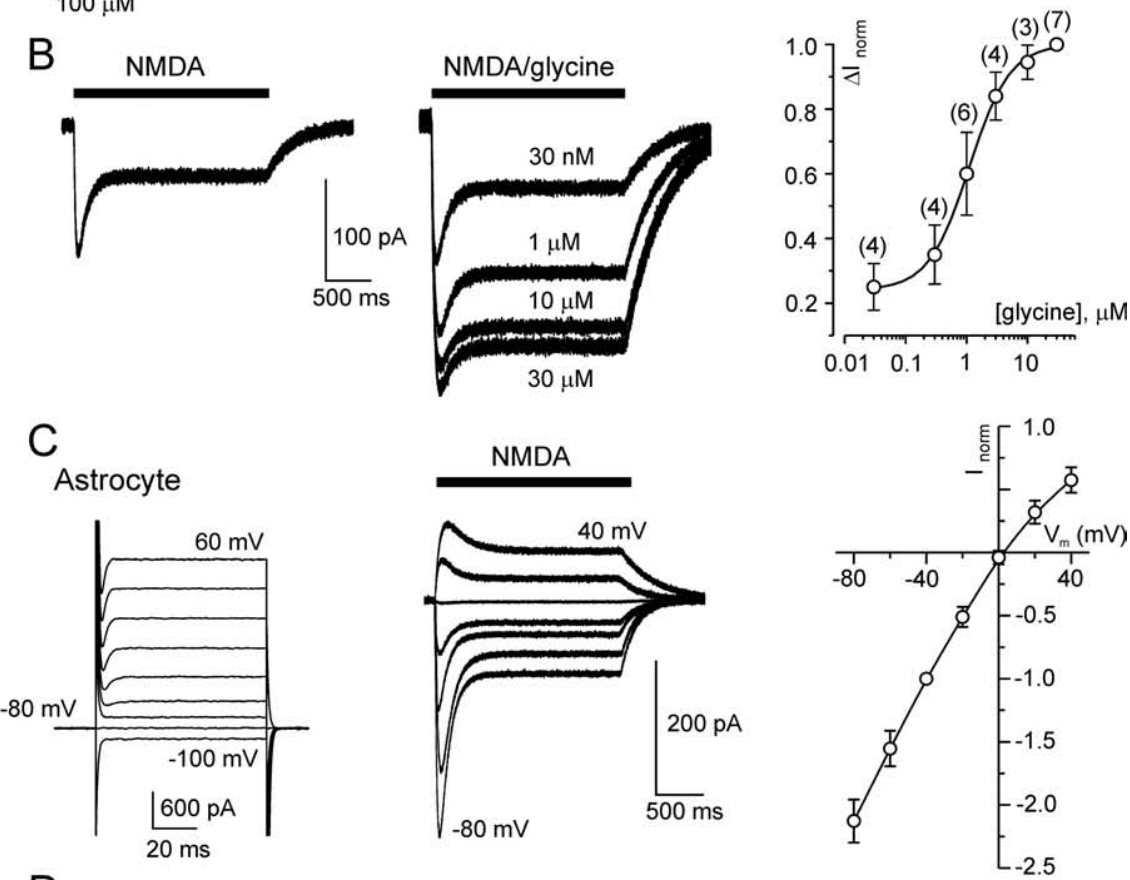

D
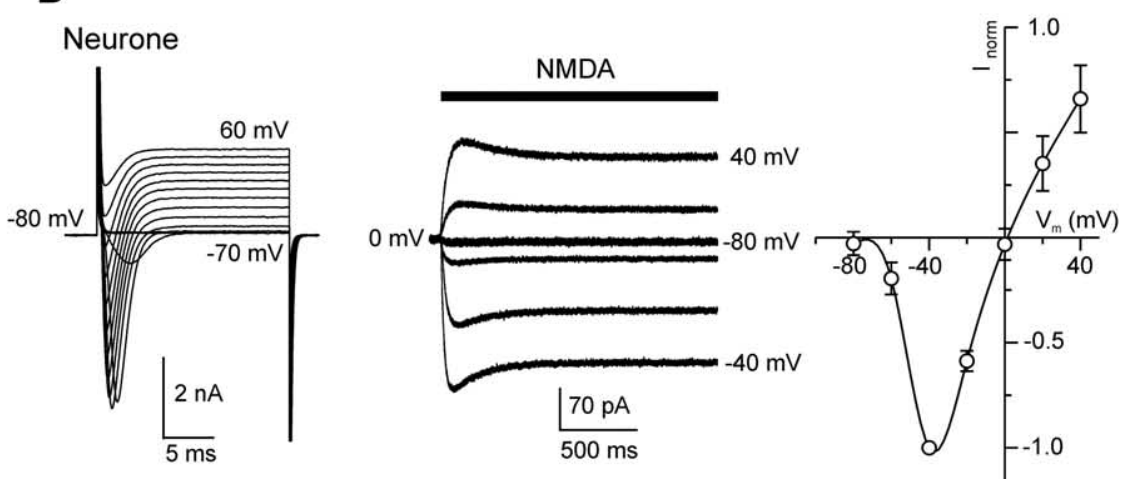

Figure 4. Comparison of NMDA-induced currents recorded from an astrocyte and a neuron isolated from the same slice. $\boldsymbol{A}$, NMDA-induced (2 s application) currents in a single astrocyte (left) and concentration-response curve constructed from six such experiments (middle; $\mathrm{EC}_{50}, 0.34 \pm 0.06 \mu \mathrm{m}$; Hill coefficient, 1.5). The right panel shows the neuron (N) and astrocyte (A) from which the recordings were made in $\mathbf{C}$ and $\mathbf{D}$. $\boldsymbol{B}$, Glycine-dependent potentiation of astrocyte NMDA response. NMDA-induced currents in glycine-free normal extracellular solution are shown on the left; NMDA-induced currents in the presence of different glycine concentrations ( $30 \mathrm{~nm}, 1 \mu \mathrm{m}, 10 \mu \mathrm{m}$, and $30 \mu \mathrm{m}$ ) are displayed in the middle. The concentration-response curve $\left(\Delta I_{\text {norm }}\right.$ represents the amplitudes of current increase normalized to the maximal increase at $30 \mu \mathrm{m}$ glycine) constructed from seven experiments is shown on the right ( $\mathrm{EC}_{50}, 1.1 \pm 0.07 \mu \mathrm{m}$; Hill coefficient, 1.2). $\mathrm{C}$, Recordings from the astrocyte. The left panel shows currents in response to short voltage pulses. The middle panel shows currents recorded at different holding potentials $(-80$ to $40 \mathrm{mV} ; 20 \mathrm{mV}$ increment) in response to NMDA $(10 \mu \mathrm{M})$. The right panel shows the current-voltage curve constructed from eight independent experiments (currents normalized to the value at $-40 \mathrm{mV}$ ). C, Recordings from the neuron. The left panel shows currents in response to short voltage pulses; depolarization induces inward and outward current characteristic of neurons. The middle panel shows the currents evoked by $10 \mu \mathrm{MNMDA}$ (holding potentials from -80 to $40 \mathrm{mV} ; 20 \mathrm{mV}$ increment). The right panel shows the current-voltage curve from four separate experiments (currents were normalized to the value measured at -40 $\mathrm{mV})$. Note the typical region of negative slope conductance between $-80 \mathrm{and}-40 \mathrm{mV}$. Extracellular $\mathrm{Mg}^{2+}$ concentration was $1 \mathrm{~mm}$ throughout. Error bars represent SD. [a,d] cyclohepten-5,10-imine maleate (MK-801) in all eight cells tested (Fig. 6A). The block developed in a use-dependent manner. The NMDA-evoked current gradually recovered after removal of MK801 when NMDA was applied repetitively at a membrane potential of $40 \mathrm{mV}$ (Fig. $6 A)$. Typically, the recovery of NMDA response was reached after the third or fourth application of agonist. These results are quite compatible with the idea of MK801 binding to the receptor in the open state only (Huettner and Bean, 1988). Ifenprodil $(10 \mu \mathrm{M})$ had no effect on the NMDA-evoked currents in 9 of 13 cells tested (Fig. 6B). At the same time, ifenprodil reduced the amplitude of NMDAevoked current by $46 \pm 7 \%$ in 4 cells of 13 tested (Fig. $6 B$, right).

Currents in astrocytes in tissue slices evoked by electrical stimulation Recordings were made from visually identified, fluorescent cells in brain slices that had a resting potential of $-86 \pm 5 \mathrm{mV}$ $(n=20)$, a low input resistance $(50-100$ $\mathrm{M} \Omega$ ), and no time-dependent currents when the membrane was depolarized by up to $60 \mathrm{mV}$ from a holding potential of $-80 \mathrm{mV}$ (Fig. 7C). These astrocytes were situated in layer II, and we stimulated afferents originating from layers IV-VI. Examples of inward current evoked in astrocytes are shown in Figure $7, A, B$, and $E$. These synaptic responses had a latency of 2-4 ms that was similar to the latency of excitatory synaptic currents in neurons. Evoked response measured from astrocytes had a rise time constant $23 \pm 9 \mathrm{~ms}$ $(n=20)$, and they declined with a clearly biphasic time course [faster time constant $(430 \pm 140 \mathrm{~ms} ; n=20)$ and slow time constant in the range of $4-8 \mathrm{~s}$ ].

MK-801 $(10 \mu \mathrm{M})$ progressively inhibited the evoked current, which reached $42 \pm 23 \%(n=12)$ of its initial value in the presence of the antagonist (Fig. 7A). The current remaining in the presence of $\mathrm{MK}$ 801 was further inhibited by the glutamate transporter blocker DL-TBOA (Fig. 7A). Incubation with $100 \mu \mathrm{M}$ DL-TBOA reduced the current to $51 \pm 17 \%(n=8)$ of its amplitude in the presence of MK-801 alone. When DL-TBOA $(100 \mu \mathrm{M})$ was applied before MK-801, the peak amplitude of the synaptic current was not affected, but there was a clear reduction in the slower sustained tail of the current and an increase in proportion of fast decaying component of the current (Fig. 7B). NBQX $(10 \mu \mathrm{M})$ applied in the presence of DL-TBOA did not significantly affect the amplitude of the current ( $96 \pm 6 \%$ of con- 
trol; $n=4)$. Thus, the changes in the kinetics suggest the existence of two components of the response: a fast component sensitive to MK-801 and therefore probably mediated by NMDA receptors and a slower component partially sensitive to glutamate transporter blockade. The summary data presented in Figure $7 D$ indicate that difference current $\left(I_{\text {peak }}-I_{\text {tail }}\right)$ was reduced to $11 \pm 5 \%(n=12)$ of control by MK-801. Conversely, DL-TBOA increased the amplitude (up to $138 \pm 20 \%$ of control; $n=7$ ) of this fast component, possibly by increasing the extracellular glutamate concentration resulting from uptake inhibition.

The voltage dependence of the astroglial response to synaptic stimulation was similar to that seen for the action of NMDA on isolated astrocytes (see above). The evoked current recorded in the presence of NBQX (30 $\mu \mathrm{M})$ and DL-TBOA (100 $\mu \mathrm{M})$ was linearly related to membrane potential in the control solution (1 mM magnesium) and had a reversal potential at $\sim 0$ $\mathrm{mV}$ (Fig. $7 E$ ). Increase in $\mathrm{Mg}^{2+}$ concentration in the bath solution to $5 \mathrm{~mm}$ did not affect the voltage dependence of this current $(n=5)$.

To our surprise, the synaptically evoked astroglial responses were barely sensitive to NBQX, whereas the isolated astrocytes displayed a significant NBQXsensitive component in their response to glutamate. Therefore, we decided to investigate whether inhibition of AMPA receptor desensitization by specific positive modulator cyclothiazide (CTZ) (Bertolino et al., 1993) may help to reveal the AMPAmediated component of astrocytes response to synaptic stimulation. Similarly to the experiments described above, the electrical stimulation of synaptic inputs triggered inward current in astrocytes voltage clamped at $-80 \mathrm{mV}$ (Fig. 8). Application of D-AP-5 $(30 \mu \mathrm{M})$ decreased this synaptically evoked current to $48 \pm 17 \%$ of its control value $(n=6)$. Further addition of CTZ (50 $\mu \mathrm{M})$ markedly increased the current amplitude in all six cells tested, the enhancement of current being $96 \pm 57 \%(n=6)$ of its amplitude measured in the presence of D-AP-5 alone. This CTZ-induced increase of astroglial synaptic response was completely (94 $\pm 8 \%$; $n=6)$ antagonized by addition of $30 \mu \mathrm{M}$ NBQX (Fig. 8).

We also observed miniature spontaneous currents in the presence of TTX $(1 \mu \mathrm{M})$ and picrotoxin $(100 \mu \mathrm{M})$ at holding potential $-80 \mathrm{mV}$ in 9 of 10 cortical astrocytes tested. The average amplitude of spontaneous events in control was $10.2 \pm 6.4 \mathrm{pA}$; the average frequency, rise, and decay time constants were $0.23 \pm$ $0.17 \mathrm{~Hz}, 1.1 \pm 0.3 \mathrm{~ms}$, and $9.75 \pm 2.1 \mathrm{~ms}$, respectively. These miniature currents were not sensitive to $100 \mu \mathrm{M}$ of DL-TBOA but were inhibited by glutamate receptor antagonists (Fig. 9). That is, D-AP-5 $(30 \mu \mathrm{M})$ decreased an average amplitude of miniature currents by $32 \pm 9.1 \%$ and their frequency by $57 \pm 9.2 \%(n=4)$.
B

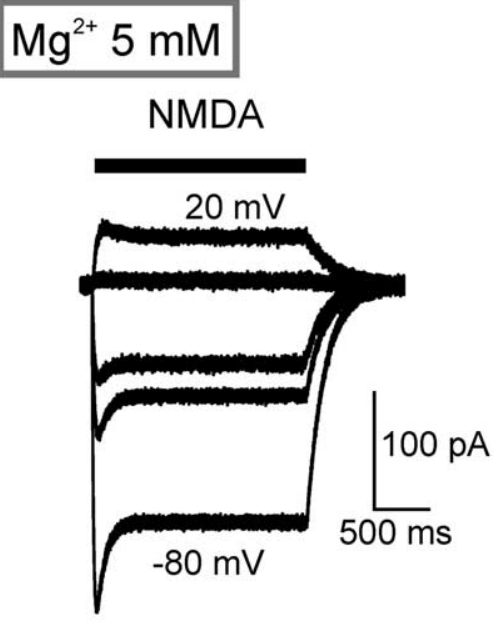

D

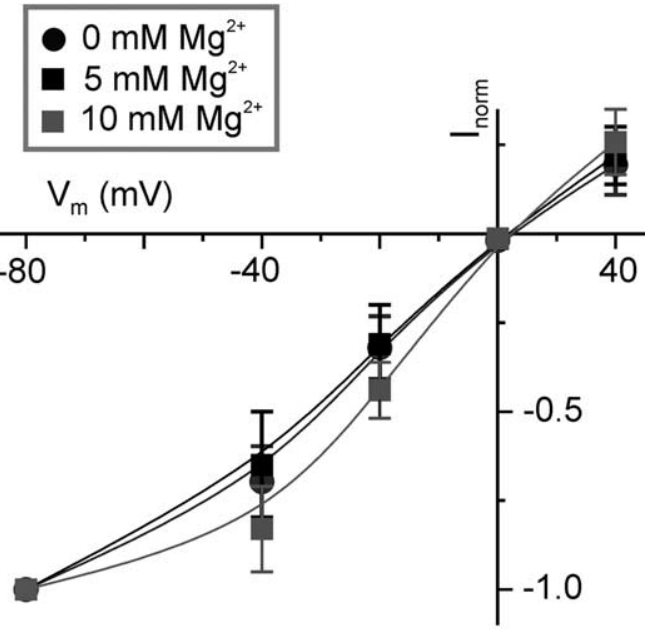

Figure 5. NMDA-induced current in astrocytes are unaffected by magnesium. $\boldsymbol{A}-\boldsymbol{C}$, Currents evoked by NMDA (10 $\mu \mathrm{M})$ at holding potentials of $-80,-40,-20,0$, and $20 \mathrm{mV}$ in the presence of a different concentration of magnesium in external $10 \mathrm{~mm}, n=4)$. The amplitudes of currents were normalized to the value measured at $-80 \mathrm{mV}$. Note that NMDA-induced currents in astrocytes are weakly affected only by high $(10 \mathrm{~mm})$ concentration of magnesium. Error bars represent SD.

The rise and decay time constants of currents recorded in presence of D-AP- 5 were $0.9 \pm 0.2$ and $8.1 \pm 1.4 \mathrm{~ms}$, respectively $(n=$ $4)$. In the presence of NBQX $(30 \mu \mathrm{M})$, the average amplitude of miniature currents was diminished by $28 \pm 10.8 \%$, and their frequency by $44 \pm 8.7 \%(n=5)$. The rise and decay time constants of currents recorded in NBQX were $1.2 \pm 0.3$ and $12.3 \pm$ $2.1 \mathrm{~ms}$, respectively $(n=5)$. The decay time of D-AP-5- and NBQX-sensitive spontaneous miniature currents was significantly different ( $p<0.05 ; t$ test). Nevertheless, this difference was substantially smaller that the difference in the decay times of D-AP-5- and NBQX-sensitive fractions of glutamate-evoked currents measured from isolated cells. At the same time, kinetics of NMDA-mediated and AMPA-mediated (the latter measured in the presence of CTZ) (Fig. 9) components of the synaptic response was quite similar. Most likely, kinetics of spontaneous versus synaptic currents in slice preparation is regulated by time 


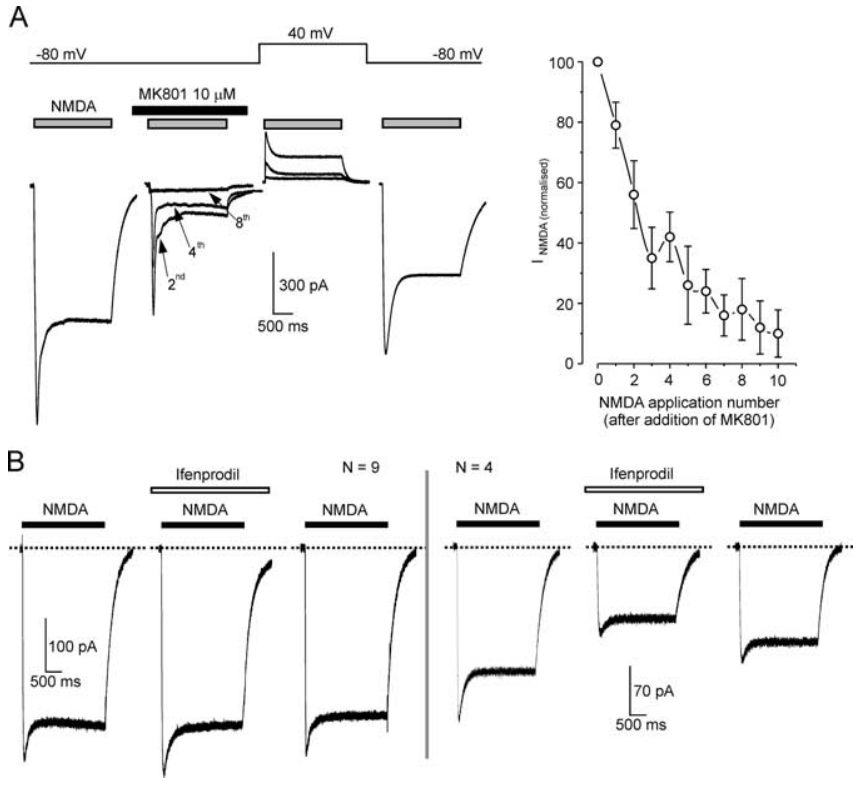

Figure 6. Pharmacological properties of NMDA-induced currents in astrocytes. $\boldsymbol{A}$, Left, Currents evoked by NMDA before, during, and after application of MK-801 (10 $\mu \mathrm{M})$. In MK-801, repeated applications of NMDA resulted in a use-dependent inhibition of the current. The current recovered after several additional NMDA applications at a positive holding potential. The holding potential protocol is shown above the current traces. The right panel shows the pooled results from several similar experiments. The amplitude of the NMDA-induced current is normalized to that before MK-801. Points represent mean \pm SD for five to eight cells. The gradual decline of current is indicative of a use-dependent block. $\boldsymbol{B}$, NMDA-induced currents in contro conditions and in the presence of ifenprodil $(10 \mu \mathrm{m})$. Note that the currents were inhibited by ifenprodil in four cells (right), whereas in the other nine cells, it failed to affect the NMDA responses.

course of glutamate delivery/removal (which is rather fast in the case of spontaneous vesicular release and quite slow in the case of spillover) rather than solely by properties of AMPA and NMDA receptors.

Simultaneous application of D-AP-5 (30 $\mu \mathrm{M})$ and NBQX (30 $\mu \mathrm{M})$ completely eliminated spontaneous events $(n=3$; data not shown). Analysis of the amplitude distribution showed that both NBQX and D-AP-5 shifted the peak of distribution toward lower amplitudes (Fig. 9, bottom). Hence, the decrease of frequency of spontaneous events under action of glutamate receptor blockers most likely results from fall of their amplitudes beyond the threshold of detection. Therefore, in contrast to the evoked response, spontaneous currents in astrocytes exhibited both NBQX- and D-AP-5-sensitive components and no sensitivity to DL-TBOA.

\section{Discussion}

\section{Cortical astrocytes possess functional NMDA receptors}

This study represents a characterization of NMDA-activated currents in astroglial cells of the mouse cortex. To achieve this, we used a nonenzymatic technique for acute isolation of astrocytes from cortical slices. This procedure reduces possible artifacts by (1) avoiding the potentially deleterious effects of enzymes and (2) avoiding the longer-term changes in receptor expression that may occur in culture. Identification of single astrocytes was possible by using transgenic mice [TgN(GFAP-EGFP)GFEC-Fki], in which the fluorescent indicator EGFP was confined to astrocytes similarly as described by Nolte et al. (2001) [line TgN(GFAPEGFP)GFEA-Fki]. The identity of astrocytes was further confirmed by their characteristic electrophysiology. In contrast to experiments performed on hippocampal and brainstem slices, which found several distinct population of astrocytes, different in their voltage-gated conductances and expression of glutamate receptors and glutamate transporters (Matthias et al., 2003; Grass et al., 2004; Wallraff et al., 2004), we failed to observe a significant heterogeneity in electrophysiological properties of cortical astroglial cells in both isolation and in acute slices. This may represent intrinsic regional differences as well as the fact that the line GFEC shows a higher percentage of bright versus low fluorescent astroglial cells (Kirchhoff, unpublished observation).

Using whole-cell voltage clamp, we showed that glutamate triggers a biphasic current in astrocytes. The first component was sensitive to the AMPA and kainate receptor blocker NBQX; the second was sensitive to D-AP-5, which is a specific blocker of NMDA receptors. In addition, the glutamate response contained a much longer lasting element, which presumably represented the activation of a glutamate transporter; in part, the latter component can be blocked by transporter inhibitor DL-TBOA. Direct application of NMDA induced an inward current in astrocytes voltage clamped at holding potential $-80 \mathrm{mV}$. Control comparative experiments on isolated neurons showed no effect of NMDA at $-80 \mathrm{mV}$; the $I-V$ relationship of the NMDA-induced current in neurons was very similar to that described in other preparations (Fig. 4D) (cf. Huettner and Bean, 1988).

\section{Astrocyte NMDA receptors are insensitive to block by magnesium ions}

The lack of effect of NMDA at $-80 \mathrm{mV}$ in neurons results from the well known block of NMDA receptors by extracellular magnesium (Mayer et al., 1984; Nowak et al., 1984). To the contrary, the $I-V$ curve for NMDA-activated currents in astrocytes was close to linear regardless of the magnesium concentration in the range $0-10 \mathrm{~mm}$. This is in contrast to a previous report (Schipke et al., 2001) in which $4 \mathrm{~mm}$ magnesium was reported to inhibit NMDA currents. Most possibly, this discrepancy stems from the different experimental conditions: in the previous experiments, NMDA currents were recorded from cells in slices, where diffusion barriers and indirect effects may impose significant difficulties in interpreting the data obtained. In our conditions, the combination of rapid drug application technique and isolated cells allowed precise control over the concentration of applied substances and eliminated the indirect effects.

It is feasible to speculate that the marked difference that we found between astrocytes and neurons is determined by a different composition of NMDA receptors expressed in these cells. At present, we are unable to uncover the exact reason for these differences. The subunit composition of NMDA receptors in astrocytes is unknown, although EGFP-expressing astroglial cells from mouse cortex were reported to express mRNAs specific for NR1, NR2B, and NR2C subunits (Schipke et al., 2001). How these subunits are assembled in astrocytes and whether some of them can be a subject for posttranslational modification remains unknown. The results of our experiments with ifenprodil, which is supposed to inhibit NR2B subunits, further add to the confusion, because ifenprodil inhibited NMDA currents only in a subpopulation of cells (4 of 13). This may indicate certain variations in subunit composition of NMDA receptors expressed in cortical astrocytes. Finally, we cannot exclude possible modification of NMDA receptors proteins by local phosphorylation or else unknown processes. Be it all as it may, the insensitivity to magnesium that we found makes good physiological sense. Astrocytes, being nonexcitable, have no obvious way to bring about the substantial depolarizations that are necessary to relieve the magne- 

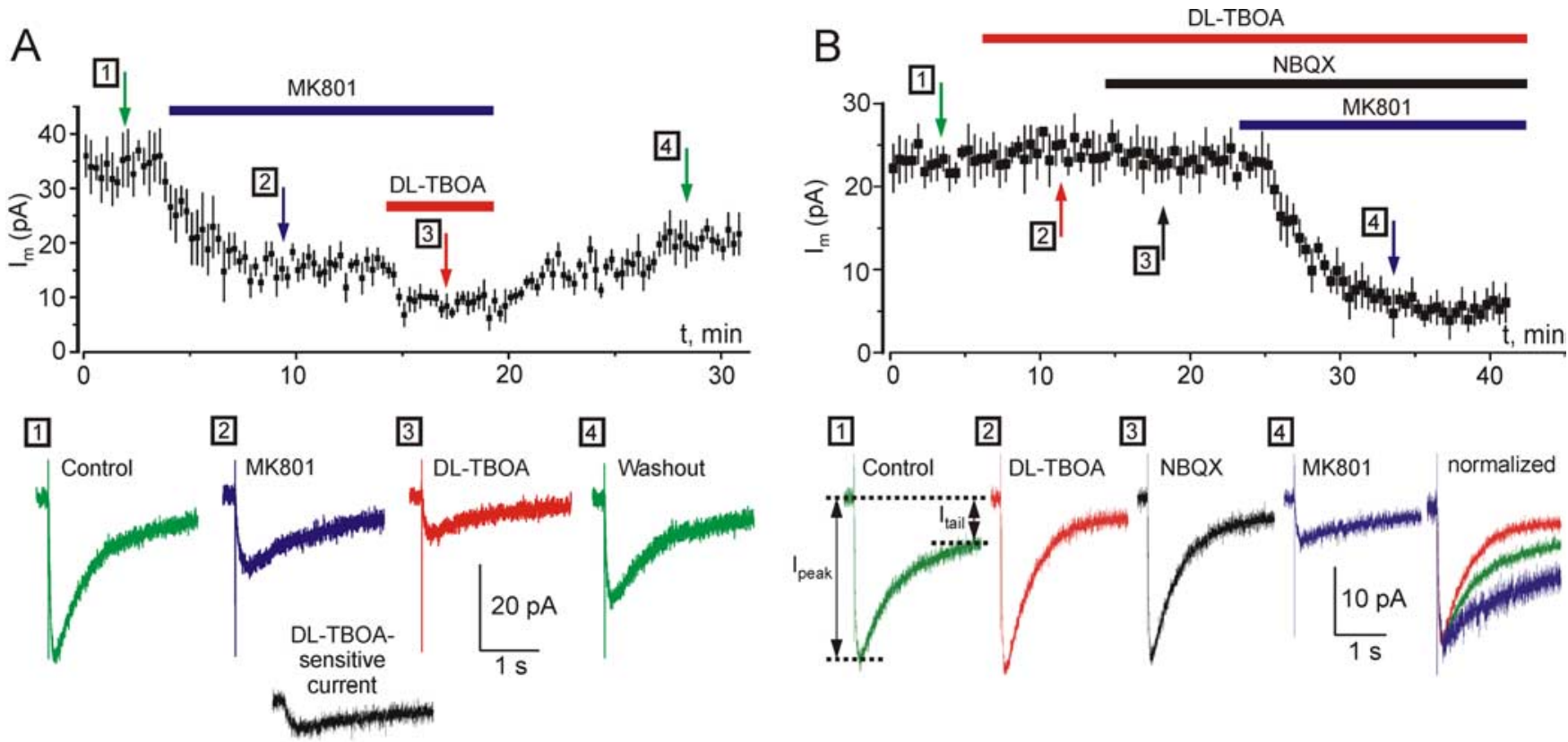

C

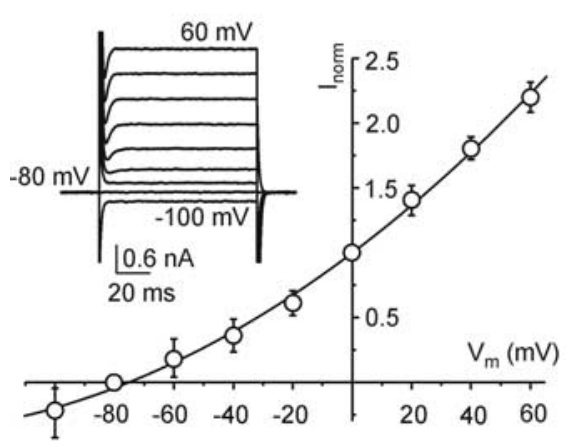

$\mathrm{D}$

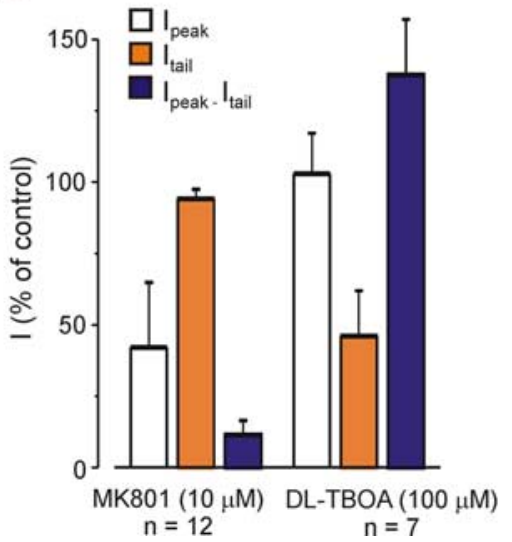

E

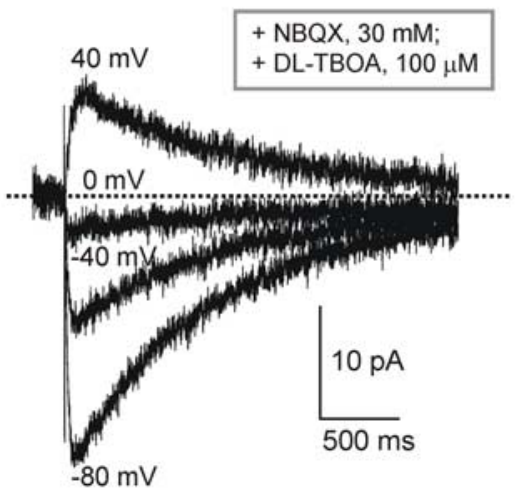

Figure 7. Synaptic currents mediated by NMDA receptors in astrocytes. Astrocytes in layer II of the slice were identified by EGFP fluorescence; electrical stimulation was in layer IV. A, Synaptically evoked currents are inhibited by MK-801 $(10 \mu \mathrm{M})$, and the residual current is partially blocked by DL-TBOA (100 $\mu \mathrm{M})$. The DL-TBOA-sensitive component obtained by subtraction is shown in the inset. $\boldsymbol{B}$, In the presence of DL-TBOA $(100 \mu \mathrm{M}), \mathrm{NBQX}(30 \mu \mathrm{M})$ has no effect on the peak synaptic current, which is then almost completely blocked by MK-801 (10 $\mu \mathrm{M})$. Each point on the time graphs represents the mean \pm SEM for five EPSCs; illustrative EPSCs are shown below. Note that the tail current was mostly blocked by DL-TBOA, whereas the initial peak current was unaffected by NBQX but blocked by MK-801. C, Current-voltage relationship for a typical astrocyte (voltage steps of $20 \mathrm{mV}$ from -100 to $+60 \mathrm{mV}$; holding potential, $-80 \mathrm{mV}$ ). Amplitudes were normalized to the value measured at $0 \mathrm{mV}\left(I_{\text {norm }}\right)$. Each point represents the mean \pm SD for seven cells. $D$, Selective inhibition of peak and tail current by MK-801 and DL-TBOA. MK-801 (10 $\left.\mu \mathrm{M}\right)$ and DL-TBOA (100 $\left.\mu \mathrm{M}\right)$ were applied separately to different astrocytes as illustrated in $\boldsymbol{A}$ and $\boldsymbol{B}$. The peak $\left(I_{\text {peak }}\right)$ and tail $\left(I_{\text {tail }}\right)$ of the current were averaged within the $20 \mathrm{~ms}$ time window as indicated in the bottom panel of $\boldsymbol{B}$; error bars are mean $\pm S E M$. The amplitudes were normalized to the values of $I_{\text {peak }} I_{\text {tail }}$ and $I_{\text {peak }}-I_{\text {tail }}$ before drug application. $\boldsymbol{E}$, Voltage dependence of synaptic currents in astrocytes. Note the reversal close to $0 \mathrm{mV}$ and the almost linear relationship between current and voltage. Currents were recorded in the presence of NBQX ( $30 \mathrm{~mm})$ and DL-TBOA $(100 \mathrm{mM}) . I_{\mathrm{m}}, A \mathrm{mplitude}$ of membrane current.

sium block found in neurons. Thus, this property of the NMDA receptors would allow astrocytes to be depolarized by glutamate even at their negative resting potentials (typically around $-80 \mathrm{mV}$ ).

\section{NMDARs are involved in neuronal-glial communications}

Recordings from astrocytes in brain slices showed that stimulation of neuronal afferents originating from layers IV-VI evokes currents in astroglial cells in layer II. These synaptic currents had very different time course from neuronal EPSCs, generally lasting for several seconds. The long-lasting current tail most likely reflects activation of a glutamate/sodium transporter: similar transporter currents have been reported in Bergmann glial cells (Clark and Barbour, 1997). However, in the case of cortical astrocytes, the larger initial part of the response was associated with activation of NMDA receptors, because it was substantially blocked by MK-801. In contrast, the lack of effect of NBQX on synaptically activated currents in astrocytes indicates the absence of an AMPA receptor-mediated component. At the same time, NBQX has a considerable inhibitory effect on fast component of astroglial response to exogenously applied glutamate (Figs. 2, 3), indicating the presence of functional AMPA receptors. This discrepancy might result from the relatively low glutamate concentrations seen by astroglial membrane after stimulation of neuronal afferents. Indeed, our direct experiments have demonstrated that astroglial NMDA receptors are $\sim 20$ times more sensitive to glutamate compared with AMPA receptors in the same cells (Fig. 3). It 


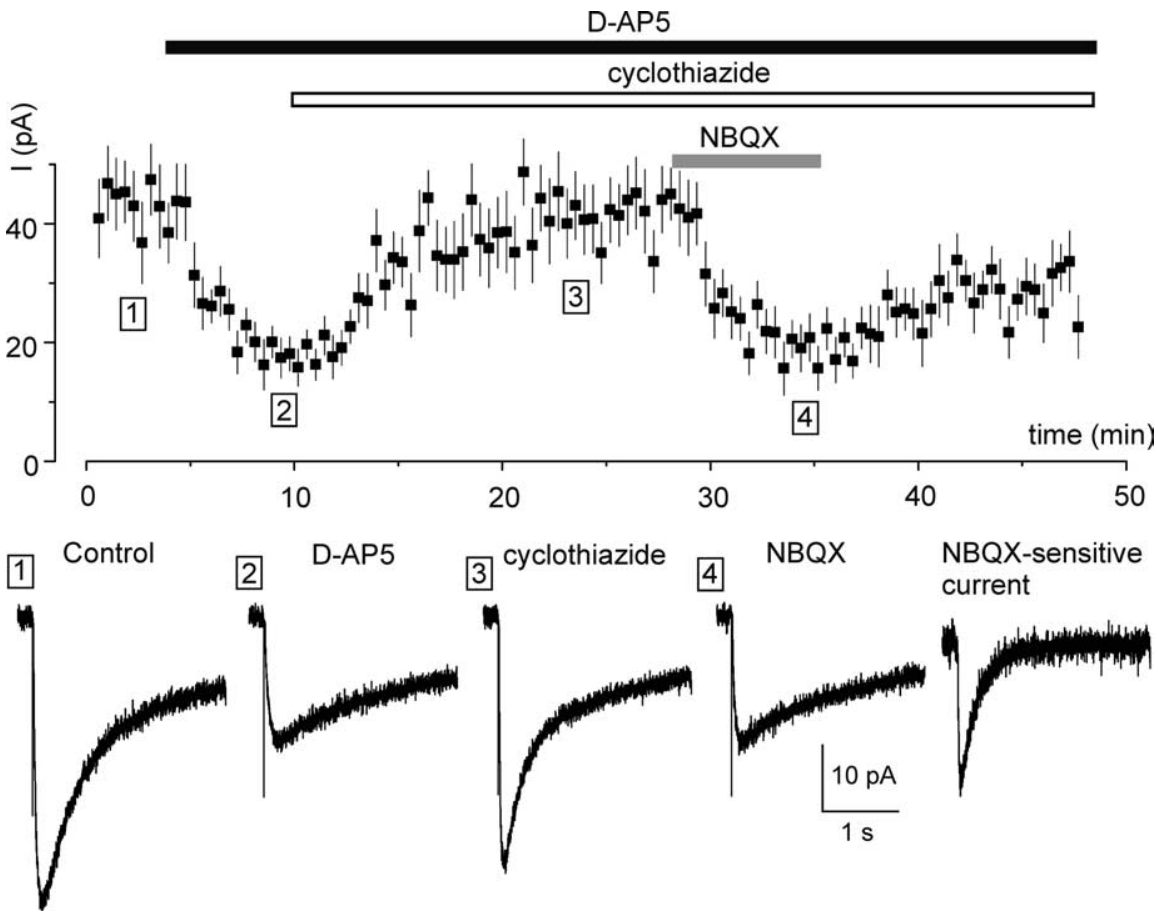

Figure 8. Inhibition of AMPA receptor desensitization reveals the NBQX-sensitive synaptic current component that appears in astrocytes. Top, Time course of synaptic current recorded in an astrocyte identified in neocortical layer II by GFEP fluorescence. Each point represents the mean \pm SEM for five EPSCS. Bottom, Illustrative currents recorded in control and after consecutive application of D-AP-5 $(30 \mu \mathrm{m})$, cyclothiazide $(50 \mu \mathrm{M})$, and NBQX $(30 \mu \mathrm{M})$. The NBQX-sensitive current was obtained by digital subtraction of currents recorded before and after application of NBQX. The NBQX-sensitive current had a rise time of $16 \pm 8 \mathrm{~ms}$ and decay time of $280 \pm 90 \mathrm{~ms}(n=6)$.
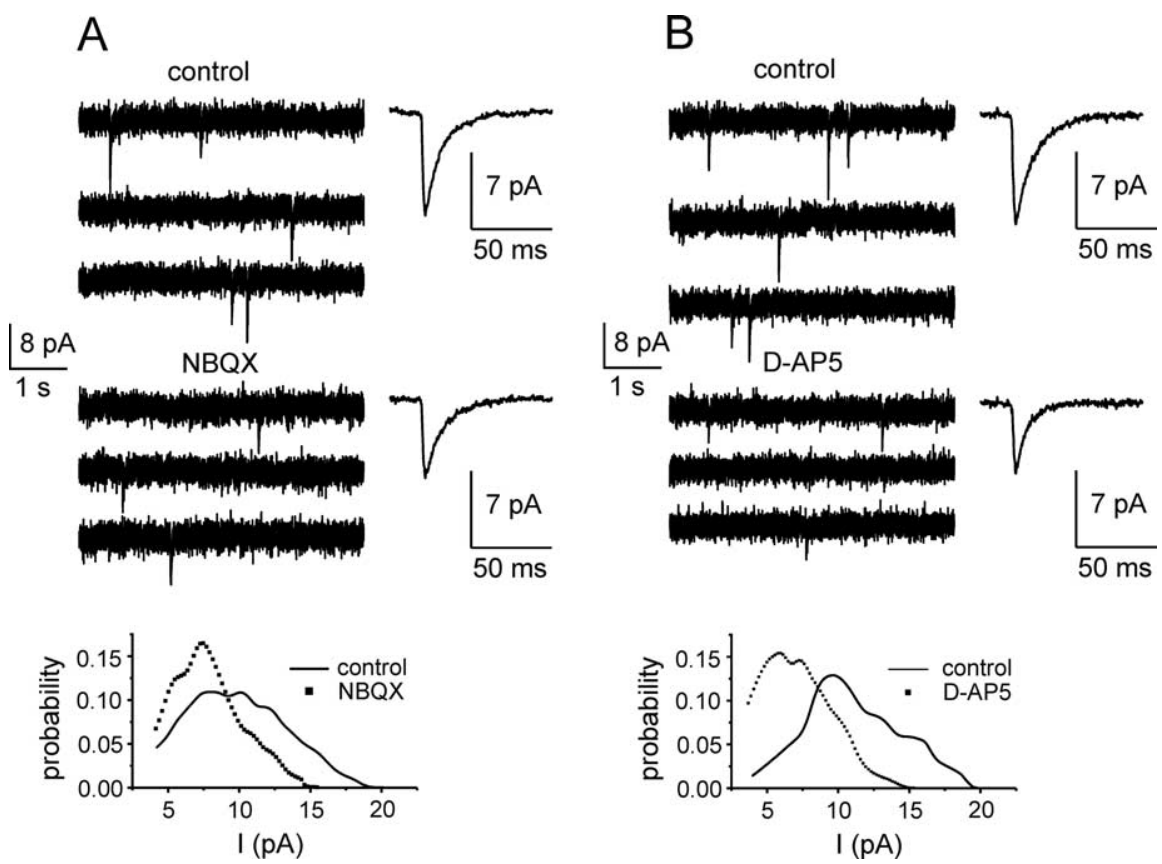

Figure 9. Miniature spontaneous excitatory currents in cortical astrocytes are mediated by AMPA and NMDA glutamate receptors. $\boldsymbol{A}$, Representative whole-cell recordings in control and after application of NBQX (30 mM). The right panels represent generalized waveform of spontaneous currents (average of 50 events). The bottom graph shows probability density function of spontaneous currents in control (solid line) and in the presence of NBQX (dots). B, Representative whole-cell recordings from astrocytes in cortical slice in control and after application of D-AP-5 $(30 \mu \mathrm{M})$. The right panel shows a generalized waveform of spontaneous currents (average of 50 events). The bottom graph shows probability density function of spontaneous currents in control (solid line) and in the presence of D-AP-5 (dots). All recordings were made at a holding potential of $-80 \mathrm{mV}$ in the presence of TTX $(1 \mu \mathrm{M})$, picrotoxin $(100 \mu \mathrm{M})$, and DL-TBOA (100 $\mu \mathrm{M})$. Note the significant decrease in the amplitude of spontaneous current as well as leftward shift of amplitude distributions under action of glutamate receptor antagonists. is conceivable to assume that astrocytic membrane faces mostly the glutamate slipped over from the synaptic cleft, which may result in relatively low concentrations of the transmitter affecting astroglial cell membrane. Indeed, investigations of spillover phenomena indicate that the concentration of glutamate beyond the synaptic cleft may be as low as 1-10 $\mu \mathrm{M}$ (Kullmann et al., 1999; Pankratov and Krishtal, 2003); this level of glutamate is sufficient for activation of extrasynaptic NMDA receptors, but it is not enough to activate AMPA receptors; at the same time, this concentration is sufficient to desensitize the AMPA receptors. This suggestion is farther supported by the fact that when desensitization of AMPA receptors was removed by slices treatment with cyclothiazide, the synaptic stimulation evoked significant AMPA-mediated current response.

When recording from astrocytes in slices, we also observed fast spontaneous miniature currents, which exhibited both AMPA and NMDA receptor-mediated components. These events most likely resulted from exposure of limited portions of astrocyte membrane to local rapid transients of high concentration of glutamate. The similar events, activated by the ectopic release of neurotransmitter, have been reported recently for cerebellar Bergman glial cells (Matsui et al., 2005). Ectopic release of neurotransmitter is direct and fast pathway of neuron-glial communications. Out data suggest that this form of signal transmission may be also intrinsic for the neocortex.

The finding that predominant component of the current response of cortical astrocytes to synaptic stimulation is mediated by NMDA receptors may have important physiological consequences. First, the NMDA current considerably outlasts the synaptic transmission event and may create significant $\mathrm{Ca}^{2+}$ entry into the astrocyte(s) surrounding the active synapse. This $\mathrm{Ca}^{2+}$ entry, in turn, can produce astroglial $\mathrm{Ca}^{2+}$ signals relevant for coordination of astroglial function with on-going synaptic activity in the cortex. Second, the endowment of astroglial membrane with two sets of receptors with different sensitivity to glutamate can allow astrocytes to detect the levels of extracellular glutamate, with NMDA receptors being activated at low levels of the transmitter, and AMPA receptors being operative at high glutamate concentrations, possibly associated with the ectopic release of the neurotransmitter. Finally, it remains unclear whether the neuronal-to-glial communication mediated by NMDA receptors 
occur only in cortex, or they may also be present in other brain regions. The NMDA receptor proteins were predominantly identified in cortical astrocytes (Conti et al., 1997, 1999) but not in hippocampus (Krebs et al., 2003); there are some indications for NMDA receptors expression in astroglial cells in nucleus locus ceruleus (Van Bockstaele and Colago, 1996). Interestingly, reactive gliosis induced by ischemia led to an appearance of NMDA receptor subunits in hippocampal astrocytes (Gottlieb and Matute, 1997; Krebs et al., 2003). Functional analysis generally demonstrated that cultures astroglial cells are devoid of NMDA receptors (Kettenmann and Schachner, 1985); similarly, electrophysiological investigations failed to detect NMDAinduced currents in the brainstem (Akopian et al., 1997). In hippocampal slices, NMDA application triggered astroglial $\mathrm{Ca}^{2+}$ signals, which, however, were often inhibited by TTX (Porter and McCarthy, 1995); likewise, NMDA evoked currents in small proportion of hippocampal astrocytes in slices (Steinhauser et al., 1994) but never in freshly isolated cells (Steinhauser and Gallo, 1996), indicating, therefore, an indirect effects of externally applied agonist. All in all, distribution of functional NMDA receptors among astroglial cells and their role in neuronal-glial interactions require additional investigations.

\section{References}

Akaike N, Moorhouse AJ (2003) Techniques: applications of the nervebouton preparation in neuropharmacology. Trends Pharmacol Sci 24:44-47.

Akopian G, Kuprijanova E, Kressin K, Steinhuser C (1997) Analysis of ion channel expression by astrocytes in red nucleus brain stem slices of the rat. Glia 19:234-246.

Alvarez-Maubecin V, Garcia-Hernandez F, Williams JT, Van Bockstaele EJ (2000) Functional coupling between neurons and glia. J Neurosci 20:4091-4098.

Araque A, Carmignoto G, Haydon PG (2001) Dynamic signaling between astrocytes and neurons. Annu Rev Physiol 63:795-813.

Bergles DE, Tzingounis AV, Jahr CE (2002) Comparison of coupled and uncoupled currents during glutamate uptake by GLT-1 transporters. J Neurosci 22:10153-10162.

Bertolino M, Baraldi M, Parenti C, Braghiroli D, DiBella M, Vicini S, Costa E (1993) Modulation of AMPA/kainate receptors by analogues of diazoxide and cyclothiazide in thin slices of rat hippocampus. Receptors Channels 1:267-278.

Bowman CL, Kimelberg HK (1984) Excitatory amino acids directly depolarize rat brain astrocytes in primary culture. Nature 311:656-659.

Burnashev N, Khodorova A, Jonas P, Helm PJ, Wisden W, Monyer H, Seeburg PH, Sakmann B (1992) Calcium-permeable AMPA-kainate receptors in fusiform cerebellar glial cells. Science 256:1566-1570.

Chen N, Ren J, Raymond LA, Murphy TH (2001) Changes in agonist concentration dependence that are a function of duration of exposure suggest $\mathrm{N}$-methyl-D-aspartate receptor nonsaturation during synaptic stimulation. Mol Pharmacol 59:212-219.

Clark BA, Barbour B (1997) Currents evoked in Bergmann glial cells by parallel fibre stimulation in rat cerebellar slices. J Physiol (Lond) 502:335-350.

Condorelli DF, Conti F, Gallo V, Kirchhoff F, Seifert G, Steinhauser C, Verkhratsky A, Yuan X (1999) Expression and functional analysis of glutamate receptors in glial cells. Adv Exp Med Biol 468:49-67.

Conti F, DeBiasi S, Minelli A, Melone M (1996) Expression of NR1 and NR2A/B subunits of the NMDA receptor in cortical astrocytes. Glia $17: 254-258$.

Conti F, Minelli A, DeBiasi S, Melone M (1997) Neuronal and glial localization of NMDA receptors in the cerebral cortex. Mol Neurobiol 14:1-18.

Conti F, Barbaresi P, Melone M, Ducati A (1999) Neuronal and glial localization of NR1 and NR2A/B subunits of the NMDA receptor in the human cerebral cortex. Cereb Cortex 9:110-120.

Gottlieb M, Matute C (1997) Expression of ionotropic glutamate receptor subunits in glial cells of the hippocampal CA1 area following transient forebrain ischemia. J Cereb Blood Flow Metab 17:290-300.

Gotz T, Kraushaar U, Geiger J, Lubke J, Berger T, Jonas P (1997) Functional properties of AMPA and NMDA receptors expressed in identified types of basal ganglia neurons. J Neurosci 17:204-215.

Grass D, Pawlowski PG, Hirrlinger J, Papadopoulos N, Richter DW, Kirchhoff F, Hulsmann S (2004) Diversity of functional astroglial properties in the respiratory network. J Neurosci 24:1358-1365.

Grosche J, Matyash V, Moller T, Verkhratsky A, Reichenbach A, Kettenmann H (1999) Microdomains for neuron-glia interaction: parallel fiber signaling to Bergmann glial cells. Nat Neurosci 2:139-143.

Haydon PG (2001) GLIA: listening and talking to the synapse. Nat Rev Neurosci 2:185-193.

Hirrlinger J, Hulsmann S, Kirchhoff F (2004) Astroglial processes show spontaneous motility at active synaptic terminals in situ. Eur J Neurosci 20:2235-2239.

Huang YH, Sinha SR, Tanaka K, Rothstein JD, Bergles DE (2004) Astrocyte glutamate transporters regulate metabotropic glutamate receptormediated excitation of hippocampal interneurons. J Neurosci 24:4551-4559.

Huettner JE, Bean BP (1988) Block of N-methyl-D-aspartate-activated current by the anticonvulsant MK-801: selective binding to open channels. Proc Natl Acad Sci USA 85:1307-1311.

Jabaudon D, Shimamoto K, Yasuda-Kamatani Y, Scanziani M, Gahwiler BH, Gerber U (1999) Inhibition of uptake unmasks rapid extracellular turnover of glutamate of nonvesicular origin. Proc Natl Acad Sci USA 96:8733-8738.

Jabs R, Kirchhoff F, Kettenmann H, Steinhauser C (1994) Kainate activates $\mathrm{Ca}^{2+}$-permeable glutamate receptors and blocks voltage-gated $\mathrm{K}^{+}$currents in glial cells of mouse hippocampal slices. Pflügers Arch 426:310-319.

Johnson JW, Ascher P (1990) Voltage-dependent block by intracellular $\mathrm{Mg}^{2+}$ of $\mathrm{N}$-methyl-D-aspartate-activated channels. Biophys J 57:1085-1090.

Kettenmann H, Schachner M (1985) Pharmacological properties of $\gamma$-aminobutyric acid-, glutamate-, and aspartate-induced depolarizations in cultured astrocytes. J Neurosci 5:3295-3301.

Kettenmann H, Backus KH, Schachner M (1984) Aspartate, glutamate and gamma-aminobutyric acid depolarize cultured astrocytes. Neurosci Lett $52: 25-29$.

Kirischuk S, Kirchhoff F, Matyash V, Kettenmann H, Verkhratsky A (1999) Glutamate-triggered calcium signalling in mouse Bergmann glial cells in situ: role of inositol-1,4,5-trisphosphate-mediated intracellular calcium release. Neuroscience 92:1051-1059.

Kondoh T, Nishizaki T, Aihara H, Tamaki N (2001) NMDA-responsible, APV-insensitive receptor in cultured human astrocytes. Life Sci 68:1761-1767.

Krebs C, Fernandes HB, Sheldon C, Raymond LA, Baimbridge KG (2003) Functional NMDA receptor subtype 2B is expressed in astrocytes after ischemia in vivo and anoxia in vitro. J Neurosci 23:3364-3372.

Kullmann DM, Min MY, Asztely F, Rusakov DA (1999) Extracellular glutamate diffusion determines the occupancy of glutamate receptors at CA1 synapses in the hippocampus. Philos Trans R Soc Lond B Biol Sci 354:395-402.

Lalo UV, Pankratov YV, Arndts D, Krishtal OA (2001) Omega-conotoxin GVIA potently inhibits the currents mediated by P2X receptors in rat DRG neurons. Brain Res Bull 54:507-512.

Malatesta P, Hack MA, Hartfuss E, Kettenmann H, Klinkert W, Kirchhoff F, Gotz M (2003) Neuronal or glial progeny: regional differences in radial glia fate. Neuron 37:751-764.

Marcaggi P, Attwell D (2004) Role of glial amino acid transporters in synaptic transmission and brain energetics. Glia 47:217-225.

Matsui K, Jahr CE, Rubio ME (2005) High-concentration rapid transients of glutamate mediate neural-glial communication via ectopic release. J Neurosci 25:7538-7547.

Matthias K, Kirchhoff F, Seifert G, Huttmann K, Matyash M, Kettenmann H, Steinhauser C (2003) Segregated expression of AMPA-type glutamate receptors and glutamate transporters defines distinct astrocyte populations in the mouse hippocampus. J Neurosci 23:1750-1758.

Mayer ML, Westbrook GL, Guthrie PB (1984) Voltage-dependent block by $\mathrm{Mg}^{2+}$ of NMDA responses in spinal cord neurones. Nature 309:261-263. Mori H, Mishina M (1995) Structure and function of the NMDA receptor channel. Neuropharmacology 34:1219-1237.

Muller T, Moller T, Berger T, Schnitzer J, Kettenmann H (1992) Calcium 
entry through kainate receptors and resulting potassium-channel blockade in Bergmann glial cells. Science 256:1563-1566.

Muller T, Grosche J, Ohlemeyer C, Kettenmann H (1993) NMDA-activated currents in Bergmann glial cells. NeuroReport 4:671-674.

Nadarajah B, Thomaidou D, Evans WH, Parnavelas JG (1996) Gap junctions in the adult cerebral cortex: regional differences in their distribution and cellular expression of connexins. J Comp Neurol 376:326-342.

Nedergaard M (1994) Direct signaling from astrocytes to neurons in cultures of mammalian brain cells. Science 263:1768-1771.

Nolte C, Matyash M, Pivneva T, Schipke CG, Ohlemeyer C, Hanisch UK, Kirchhoff F, Kettenmann H (2001) GFAP promoter-controlled EGFPexpressing transgenic mice: a tool to visualize astrocytes and astrogliosis in living brain tissue. Glia 33:72-86.

Nowak L, Bregestovski P, Ascher P, Herbet A, Prochiantz A (1984) Magnesium gates glutamate-activated channels in mouse central neurones. Nature 307:462-465.

Pakhotin P, Verkhratsky A (2005) Electrical synapses between Bergmann glial cells and Purkinje neurones in rat cerebellar slices. Mol Cell Neurosci 28:79-84.

Pankratov Y, Lalo U, Krishtal O, Verkhratsky A (2002) Ionotropic P2X purinoreceptors mediate synaptic transmission in rat pyramidal neurones of layer II/III of somato-sensory cortex. J Physiol (Lond) 542:529-536.

Pankratov Y, Lalo U, Krishtal O, Verkhratsky A (2003) P2X receptormediated excitatory synaptic currents in somatosensory cortex. Mol Cell Neurosci 24:842-849.

Pankratov YV, Krishtal OA (2003) Distinct quantal features of AMPA and NMDA synaptic currents in hippocampal neurons: implication of glutamate spillover and receptor saturation. Biophys J 85:3375-3387.

Porter JT, McCarthy KD (1995) GFAP-positive hippocampal astrocytes in situ respond to glutamatergic neuroligands with increases in $\left[\mathrm{Ca}^{2+}\right]_{\mathrm{i}}$. Glia 13:101-112.

Randle JC, Guet T, Cordi A, Lepagnol JM (1992) Competitive inhibition by NBQX of kainate/AMPA receptor currents and excitatory synaptic potentials: importance of 6-nitro substitution. Eur J Pharmacol 215:237-244.

Schipke CG, Ohlemeyer C, Matyash M, Nolte C, Kettenmann H, Kirchhoff F (2001) Astrocytes of the mouse neocortex express functional $N$-methylD-aspartate receptors. FASEB J 15:1270-1272.
Seifert G, Rehn L, Weber M, Steinhauser C (1997) AMPA receptor subunits expressed by single astrocytes in the juvenile mouse hippocampus. Brain Res Mol Brain Res 47:286-294.

Shao Y, McCarthy KD (1997) Responses of Bergmann glia and granule neurons in situ to $N$-methyl-D-aspartate, norepinephrine, and high potassium. J Neurochem 68:2405-2411.

Steinhauser C, Gallo V (1996) News on glutamate receptors in glial cells. Trends Neurosci 19:339-345.

Steinhauser C, Jabs R, Kettenmann H (1994) Properties of GABA and glutamate responses in identified glial cells of the mouse hippocampal slice. Hippocampus 4:19-35.

Stricker C, Field AC, Redman SJ (1996) Changes in quantal parameters of EPSCs in rat CA1 neurones in vitro after the induction of long-term potentiation. J Physiol (Lond) 490:443-454.

Van Bockstaele EJ, Colago EE (1996) Selective distribution of the NMDA-R1 glutamate receptor in astrocytes and presynaptic axon terminals in the nucleus locus coeruleus of the rat brain: an immunoelectron microscopic study. J Comp Neurol 369:483-496.

Verkhratsky A, Kettenmann H (1996) Calcium signalling in glial cells. Trends Neurosci 19:346-352.

Verkhratsky A, Steinhauser C (2000) Ion channels in glial cells. Brain Res Brain Res Rev 32:380-412.

Verkhratsky A, Orkand RK, Kettenmann H (1998) Glial calcium: homeostasis and signaling function. Physiol Rev 78:99-141.

Volterra A, Meldolesi J (2005) Astrocytes, from brain glue to communication elements: the revolution continues. Nat Rev Neurosci 6:626-640.

Vorobjev VS (1991) Vibrodissociation of sliced mammalian nervous tissue. J Neurosci Methods 38:145-150.

Wallraff A, Odermatt B, Willecke K, Steinhauser C (2004) Distinct types of astroglial cells in the hippocampus differ in gap junction coupling. Glia 48:36-43.

Wyllie DJ, Behe P, Nassar M, Schoepfer R, Colquhoun D (1996) Singlechannel currents from recombinant NMDA NR1a/NR2D receptors expressed in Xenopus oocytes. Proc Biol Sci 263:1079-1086.

Ziak D, Chvatal A, Sykova E (1998) Glutamate-, kainate- and NMDAevoked membrane currents in identified glial cells in rat spinal cord slice. Physiol Res 47:365-375. 